January 2022

\title{
Admission Variables Predict Success in a Hybrid-online Physical Therapist Education Program
}

\author{
Evan M. Pucillo \\ University of St. Augustine for Health Sciences, epucillo@usa.edu \\ Rossniel Marinas \\ University of St. Augustine for Health Sciences, rmarinas@usa.edu \\ Christine Salmon \\ University of St. Augustine for Health Sciences, csalmon@usa.edu \\ Vibhor Agrawal \\ University of St. Augustine for Health Sciences, vagrawal@usa.edu
}

Follow this and additional works at: https://nsuworks.nova.edu/ijahsp

Part of the Educational Assessment, Evaluation, and Research Commons, Higher Education Commons, and the Physical Therapy Commons

\section{Recommended Citation}

Pucillo EM, Marinas R, Salmon C, Agrawal V. Admission Variables Predict Success in a Hybrid-online Physical Therapist Education Program. The Internet Journal of Allied Health Sciences and Practice. 2022 Jan 04;20(1), Article 18.

This Manuscript is brought to you for free and open access by the College of Health Care Sciences at NSUWorks. It has been accepted for inclusion in Internet Journal of Allied Health Sciences and Practice by an authorized editor of NSUWorks. For more information, please contact nsuworks@nova.edu. 


\title{
Admission Variables Predict Success in a Hybrid-online Physical Therapist Education Program
}

\begin{abstract}
Purpose: Screening student applicants can be a valuable measure for hybrid-online Doctor of Physical Therapy (DPT) programs.Institutions embrace a wide variety of measurements that drive admissions decisions. However, uncertainties exist regarding the most accurate admission predictors of academic outcomes, especially among hybrid-online DPT programs. The purpose of this study was to examine predictive relationships between applicants' admission variables and program grade point average and National Physical Therapy Examination (NPTE) performance in a cohort of entry-level hybrid-online DPT students. Methods: A retrospective cohort design and convenience sampling method was used across two entry-level hybrid-online DPT programs in the Southeastern US. Hybrid-online DPT programs utilized $\geq 51 \%$ online instructional delivery. Applicants' undergraduate admissions records, DPT program academic records, and NPTE scores were collected. Multiple linear regression analyses tested the hypotheses. Cross-tabulations and McNemar's test were used to identify cut-off scores for variables and odds-ratios of passing the NPTE. Results: $\mathrm{N}=377$ were collected and analyzed from two hybrid-online DPT programs $(\mathrm{N}=143$ [38\%] Program A; $\mathrm{N}=234$ [62\%] Program B) between Fall of 2018 and Spring of 2020. Applicant undergraduate (UGPA) and trending (tGPA)(final 60 credits) predicted first-time NPTE pass rate $\left(r^{2}=\right.$ $0.30, \mathrm{p} 2=0.18, \mathrm{p} 2=0.26, \mathrm{p}=0.02), \mathrm{F}(6,370)$. Applicant uGPA and tGPA were associated with 3-fold and 2-fold increase odds of passing NPTE on the first attempt, respectively. Conclusions: This study suggests certain applicant variables may be more indicative of success and could be weighted more heavily during the application process. Cumulative and trending undergraduate GPA accurately predict academic performance in hybrid-online DPT education, and NPTE scores. Notably, GRE and undergraduate science GPA were unremarkable. Hybrid-online DPT program GPA strongly predicts outcomes in NPTE scores.
\end{abstract}

\section{Author Bio(s)}

Evan M. Pucillo, PT, DPT, EdD is Assistant Professor of Physical Therapy at the University of St. Augustine for Health Sciences in St. Augustine, FL where he teaches research and clinical neuroanatomy.

Rossniel Marinas, PT, DPT, is an Assistant Professor of Physical Therapy at the University of St. Augustine for Health Sciences in Miami, FL, where he teaches pathophysiology, pharmacology, and pediatric physical therapy.

Christine Salmon, PT, DPT, is an Assistant Professor of Physical Therapy at the University of St. Augustine for Health Sciences in Miami, FL, where she teaches patient care management, physical therapy for the integumentary and lymphatic systems, and geriatric physical therapy.

Vibhor Agrawal, PhD is an Associate Professor of Physical Therapy and Research Director at the University of St. Augustine for Health Sciences in Miami, FL.

\section{Acknowledgements}

Acknowledgements The authors would like to thank the following university personnel for their assistance with this investigation: Nga Pham, PhD, Executive Director, Institutional Research and Assessment Tobi Baldwin, PT, PhD, Director of Curriculum Quality Jackie Crossen-Sills, PT, PhD, Associate Dean, College of Rehabilitation Sciences Alicia Day, Admissions Specialist Julie Gonick, Vice President, Enrollment Management Diane Rondinelli, Registrar Author Contributions Conceptualization: CS, EP, RM, VA. Methodology: CS, EP, RM, VA. Project administration: EP, VA. Data curation: EP, VA. Formal analysis: EP, VA.

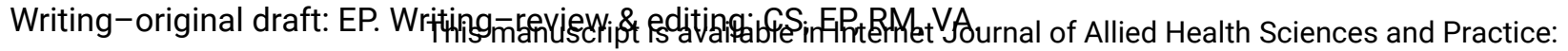




\title{
IIJAHSP \\ The Internet Joutnal of Allied Health Sciences and Practice \\ Dedicated to allied health professional practice and education \\ Vol. 20 No. 1 ISSN 1540-580X
}

\section{Admission Variables Predict Success in a Hybrid-online Physical Therapist Education Program}

\author{
Evan M. Pucillo \\ Rossniel Marinas \\ Christine Salmon \\ Vibhor Agrawal \\ University of St. Augustine for Health Sciences \\ United States
}

\begin{abstract}
Purpose: Screening student applicants can be a valuable measure for hybrid-online Doctor of Physical Therapy (DPT) programs. Institutions embrace a wide variety of measurements that drive admissions decisions. However, uncertainties exist regarding the most accurate admission predictors of academic outcomes, especially among hybrid-online DPT programs. The purpose of this study was to examine predictive relationships between applicants' admission variables and program grade point average and National Physical Therapy Examination (NPTE) performance in a cohort of entry-level hybrid-online DPT students. Methods: A retrospective cohort design and convenience sampling method was used across two entry-level hybrid-online DPT programs in the Southeastern US. Hybrid-online DPT programs utilized $\geq 51 \%$ online instructional delivery. Applicants' undergraduate admissions records, DPT program academic records, and NPTE scores were collected. Multiple linear regression analyses tested the hypotheses. Cross-tabulations and McNemar's test were used to identify cut-off scores for variables and odds-ratios of passing the NPTE. Results: N=377 were collected and analyzed from two hybrid-online DPT programs ( $N=143$ [38\%] Program A; $N=234$ [62\%] Program B) between Fall of 2018 and Spring of 2020. Applicant undergraduate (uGPA) and trending (tGPA)(final 60 credits) predicted first-time NPTE pass rate $\left(r^{2}=0.30, p<0.01\right),\left(r^{2}=0.18, p<0.01\right), F(6,370)$, respectively. Applicant uGPA predicted failing the NPTE $(\leq 600)$ on the first attempt $\left(r^{2}=0.26, p=0.02\right), F(6,370)$. Applicant uGPA and tGPA were associated with 3-fold and 2fold increase odds of passing NPTE on the first attempt, respectively. Conclusions: This study suggests certain applicant variables may be more indicative of success and could be weighted more heavily during the application process. Cumulative and trending undergraduate GPA accurately predict academic performance in hybrid-online DPT education, and NPTE scores. Notably, GRE and undergraduate science GPA were unremarkable. Hybrid-online DPT program GPA strongly predicts outcomes in NPTE scores.
\end{abstract}

Keywords: admission variables; DPT program outcomes; GPA; NPTE score; academic success. hybrid-online 


\section{INTRODUCTION}

Physical Therapy (PT) has been categorized among the fastest-growing occupations in the United States, and entry-level doctor of physical therapy (DPT) education programs are witnessing a tremendous rate of growth. $1,2,3$ US News and World Report has steadily ranked the PT profession as one of the top 100 careers. ${ }^{4}$ Experts anticipate that the PT profession will grow by nearly 20$30 \%$ over the next decade. ${ }^{1,2,3}$ This growth is largely due to a surging demand for health care providers and an aging population.,2,3 As a result, entry-level PT education programs are rapidly expanding to meet the increased labor demands of the health workforce. ${ }^{1}$ To meet this demand, entry-level DPT programs are leveraging technological advances to include more hybrid-online learning and hybrid-online curricular models in lieu of traditional face-to-face educational delivery. ${ }^{5,6}$ As programs expand to graduate more candidates for a booming health workforce, there are significant financial interests underpinning links between applicant characteristics and outcomes for programs with hybrid-online models. ${ }^{7-10}$

In 2020, the American Physical Therapy Association (APTA) estimated that roughly $80 \%$ of DPT graduates accumulated at least $\$ 142,000$ USD of student loan debt, while median gross earnings in 2018 were around $\$ 85,000$ annually. ${ }^{11}$ As tuition continually increases, higher debt-to-earnings ratios threaten the valuation and return on investment of obtaining such a degree. ${ }^{8-10}$ Yet, the total cost of a completing a DPT education continually rises each year and typically outpaces the rate of inflation. ${ }^{11}$ According to the Commission on Accreditation of Physical Therapy Education (CAPTE), between 2010-2020 the total DPT education program costs were triple the rate of inflation over the same period of time. ${ }^{11}$ Overall, student loan debt in the US has now ballooned past $\$ 1.6$ trillion dollars. ${ }^{12}$ As the costs of DPT education programs continue to increase, greater financial imperatives underpin each admissions decision for both students and institutions. $9,10,13$ Students who may not be well-suited for the rigors of a DPT education should be screened during the application process with evidence-based and reliable measurements. ${ }^{7,14-20}$ Students experiencing academic difficulty may need to withdraw from, and remediate, more challenging courses. ${ }^{19}$ This could lead to a disruption of the normal academic progression, matriculation, and the ability to qualify for the National Physical Therapy Examination (NPTE). ${ }^{7}$ Delays in normal academic progression will likely result in additional financial hardship due to added tuition costs and the postponement of earning a professional salary.8-10 Therefore, rigorous and in-depth screening of student applicants should be viewed as a valuable cost-saving measure for all stakeholders of hybrid-online programs. ${ }^{7}$

There is value in accurately identifying stronger from weaker student applicants early in the application process. ${ }^{21-24}$ If at-risk applicants could be identified early, it may provide hybrid-online DPT programs with strategic areas for additional academic support to avoid attrition. 7,14,15,19 Entry-level DPT programs use a number of quantitative metrics for admitting applicants into their programs. $7,25-33$ In recent history, trends have shifted to represent both cognitive and non-cognitive measurements for evaluating applicants. For example, the Health Science Reasoning Test (HSRT), holistic reviews and interviews, perseverance and grit, emotional intelligence, self-efficacy, and other non-cognitive profiles have become more commonplace. ${ }^{25-33}$ Despite emerging trends to include a broader representation of non-cognitive assessments, entry-level DPT programs have long placed a strong emphasis on quantitative measures of undergraduate academic performance for admission. ${ }^{7}$ Historically, undergraduate grade point average (UGPA), undergraduate core science GPA (sciGPA), and Graduate Readiness Examination (GRE) scores have served as a bedrock for screening candidates with the highest likelihood of successful outcomes in a program.7,17,19,20 Recent evidence from a meta-analysis by Wolden et al highlights the magnitude and direction of many of these relationships; yet, institutions continue to embrace a wide variety of measurements. ${ }^{7}$ Despite ongoing attention, however, much remains unclear about the most valuable predictors for applicant success upon which an admission decision should be made, especially for hybridonline DPT programs.

As entry-level DPT education witnesses trends toward online instruction and hybridized learning, much remains to be studied about the admission variables indicative of success in this educational environment. ${ }^{34}$ There may exist a set of characteristics predictive of success that are unique to students entering hybrid-online DPT education. However, little attention has been given to understanding admissions selection criteria of hybrid-online DPT programs. As hybrid-online DPT programs increase with frequency and scale, admissions decisions are largely informed by the prior evidence based on traditional face-to-face programs. ${ }^{5}$ The purpose of this study was to examine predictive relationships between an applicants' admission variables and academic success, as well as NPTE performance, among entry-level DPT students in a hybrid-online program. This study sought to identify cut-off scoring criteria for each admission variable upon which programmatic success and NPTE passing odds-ratios could be calculated. The research questions $(\mathrm{RQ})$ for this study were:

RQ1: Which applicant admission variables can accurately predict cumulative DPT program GPA (PTGPA) or NPTE scores in a hybrid-online entry-level DPT program?

RQ2: Does PTGPA accurately predict first-time passing rate on the NPTE in a hybrid-online entry-level DPT program?

RQ3: Are there cut-off scores in applicant variables associated with increased odds of passing the NPTE on the firstattempt?

(c) The Internet Journal of Allied Health Sciences and Practice, 2022 


\section{MATERIALS AND METHODS}

This study utilized a retrospective cohort design and predictive correlational analyses to answer the research questions. A convenience sampling method was used across two campuses located in the Southeastern US. The two campuses selected were from the same institution and utilized identical curricula, yet faculty were unique to each campus. The sample consisted of three graduate cohorts per year, per campus. Retrospective sampling consisted of a total of nine cohorts of records, each consisting of roughly 50 entry-level hybrid-online DPT students. The hybrid-online curricula were characterized by at least $\geq 51 \%$ of online and $\leq 49 \%$ face-to-face instruction as defined by credit hour. Applicant admissions records, programmatic academic records, and NPTE scores were collected for all subjects from each campus database. Graduate records from two entry-level hybrid-online DPT programs were collected between Fall of 2018 to Spring of 2020. All study procedures were approved by IRB.

Undergraduate records were accessed and compared to academic performance records from each institutional registrar database. Records were excluded if any portion of a student's undergraduate, DPT program, or NPTE data were unable to be obtained for any reason. That is, all records were required to have all predictor variables and outcome variables present to qualify for final analysis. For example, if some DPT students withheld disclosure of NPTE scores to the host institution, their record was excluded from final analysis. A priori analysis determined a minimum sample of $\mathrm{N}=196$ subjects (93 student records from each campus) was needed to achieve $80 \%$ statistical power with alpha set at 0.05 for the set number of predictor variables. ${ }^{34}$ The admission predictor variables were $X_{1}$ : undergraduate cumulative GPA (uGPA), $X_{2}$ : undergraduate core science GPA (sciGPA), $X_{3}$ : pre-requisite GPA (prGPA), $X_{4}$ : trend GPA (tGPA) (calculated from final 60 credit hours of undergraduate transcript), $X_{5}$ : quantitative Graduate Readiness Examination score (GRE), and $X_{6}$ : undergraduate degree type (science or non-science). $X_{2}$ sciGPA included coursework from the natural, physical, health and/or social sciences. Similarly, $X_{6}$ undergraduate degree type, differentiated students with a degree in the aforementioned sciences, from those with a degree in the arts and humanities. The outcome variables were $Y_{1}$ : cumulative DPT program GPA (PTGPA); $Y_{2}$ : NPTE score; and $Y_{3}$ NPTE first attempt pass rate (dichotomous; pass/nopass).

Data was analyzed using IBM Statistical Package for Social Sciences (SPSS) v. 27.0 (Armonk, NY, 2020). ${ }^{35}$ To answer RQ1, a simultaneous multiple linear regression analysis was conducted. To answer RQ2, a separate simultaneous multiple linear regression was performed. Simultaneous linear regression analyses were first performed for the admission predictor variables and PTGPA, and then for admission predictor variables and NPTE scores and first-attempt NPTE pass rate. To answer RQ3, ROC analyses identified cut-off values for each predictor variable in the sample based upon the NPTE score for each record. Next, receiver operating characteristic (ROC) analyses were performed from scores across each predictor variable to identify cut-off values according to first-attempt performance on the NPTE ( $\geq 600)$. Once cut-off values were identified for each predictor variable, data were coded into a corresponding dichotomous variable for above/below cut-off values. Then, McNemar's cross tabulations were performed using above/below cut-off values to calculate the odds-ratios for each predictor variable. NPTE scores were analyzed as raw quantitative scores for regression analyses, and for pass/no-pass rates with a score of 600 being the established cut-off value.

\section{RESULTS}

A total of $\mathrm{N}=434$ student records were retrospectively collected from the two campuses. Entry-level hybrid-online DPT program graduation date ranged from 2018-2019, and NPTE administrations from 2019-2020. A final sample of $\mathrm{N}=377$ was entered for statistical analysis after 57 incomplete records were removed from the data set for failure to meet the specified inclusion criteria. Of the total $\mathrm{N}(\%)=377(100 \%)$, there were $109(28.9 \%)$ male and $268(71.1 \%)$ female records. A total of $143(38 \%)$ were included from Campus A, and 234(62\%) from Campus B. A full description and comparison of the sample characteristics by campus can be found in Table 1. Mean(SD) first-time pass rate on the NPTE for this sample of hybrid-online DPT students was $85.6 \%(3.1 \%)$. The ultimate NPTE pass rate for this sample was found to be $99.1 \%$. Although significant differences were present between Campus $A$ and $B$, both data sets were normally distributed and adhered to all assumptions tests.

Results from testing RQ1 can be found in Table 2. Findings showed that UGPA was the strongest predictor of PTGPA, $F(6,370)$, $\left(r^{2}=0.25, p<0.01\right)$, followed by tGPA $\left(r^{2}=0.15, p<0.01\right)$. The total combination of applicant admission variables (uGPA, sciGPA, prGPA, tGPA, GRE scores, and undergraduate degree type) was able to predict PTGPA $\left(r^{2}=0.26, p<0.01\right)$. However, neither undergraduate degree type, sciGPA, prGPA, or GRE scores were independently able to accurately predict PTGPA in this model.

Results from testing RQ2 can be found in Table 3. In this model, uGPA was the strongest predictor of first-time NPTE pass rate $\left(r^{2}\right.$ $=0.30, p<0.001)$, followed by tGPA $\left(r^{2}=0.18, p<0.01\right)$ and GRE score $\left(r^{2}=0.03, p<0.05\right)$. However, GRE scores narrowly achieved statistical significance and only explained $3 \%$ of variation in NPTE scores. Conversely, among the applicant admission variables, uGPA was the most significant applicant admission variable predictive of failing the NPTE $(\leq 600)$ on the first attempt $F(6,370),\left(r^{2}\right.$ $=0.26, p=0.02$ ). In this analysis, prGPA, sciGPA, and degree type were not significantly predictive of first-time pass rates on the

( The Internet Journal of Allied Health Sciences and Practice, 2022 
NPTE. The total combination of applicant admission variables (uGPA, sciGPA, prGPA, tGPA, GRE scores, and undergraduate degree type) was able to predict NPTE scores $\left(r^{2}=0.32, p<0.01\right)$. Results show that uGPA, tGPA, and GRE quantitative scores were individually able to predict NPTE score, $F(6,370),(p<0.01, p<0.01$, and $p<0.05$, respectively). Yet, PTGPA was the single most significant predictor of NPTE performance in this model and was able to explain $56 \%(p<0.01)$ of variation in the NPTE scores.

Results from testing RQ3 and can be found in Table 4. Odds-ratios were calculated according to first-time NPTE scores where $\geq 600$ was the limiting value. From the set of applicant admissions characteristics, UGPA and tGPA had the highest likelihood of passing NPTE at a multiple of 2.89, and 1.97, respectively. However, PTGPA demonstrated the highest odds-ratio, whereby PTGPA above the cut-off value yielded a $\sim 4$-fold increased odds of passing the NPTE on the first attempt.

Table 1. Descriptive characteristics of the sample by campus

\begin{tabular}{|lrrrr|}
\hline \multicolumn{1}{|c}{ Variable } & Total N(\%) & Campus A & Campus B & Comparison \\
\hline Gender & $377(100 \%)$ & $143(38 \%)$ & $234(62 \%)$ & n/a \\
$\quad$ Male N(\%) & $109(28.9 \%)$ & $41(28.7 \%)$ & $68(29.1 \%)$ & n/a \\
$\quad$ Female N(\%) & $268(71.1 \%)$ & $102(71.3 \%)$ & $166(70.9 \%)$ & n/a \\
Undergraduate degree type & & & & \\
$\quad$ Science & $340(90.1 \%)$ & $122(85.3 \%)$ & $218(93.2 \%)$ & n/a \\
$\quad$ Non-science & $37(9.9 \%)$ & $21(14.7 \%)$ & $16(43.2 \%)$ & n/a \\
& & & & \\
\hline Applicant Admission Variable & Mean (SD) & Mean (SD) & Mean (SD) & \\
\hline uGPA & $3.43(0.27)$ & $3.29(0.29)$ & $3.44(0.26)$ & $\mathrm{p}<0.01$ \\
sciGPA & $3.34(0.27)$ & $3.29(0.29)$ & $3.36(0.26)$ & $\mathrm{p}=0.28$ \\
prGPA & $3.44(0.23)$ & $3.39(0.24)$ & $3.46(0.22)$ & $\mathrm{p}=0.23$ \\
tGPA & $3.49(0.29)$ & $3.46(0.32)$ & $3.51(0.28)$ & $\mathrm{p}<0.05$ \\
GRE quantitative score & $299.1(6.97)$ & $295.4(11.5)$ & $300.1(5.6)$ & $\mathrm{p}=0.08$ \\
& & & & \\
Outcome Variable & & & & \\
PTGPA & $3.42(0.27)$ & $3.40(0.27)$ & $3.43(0.26)$ & $\mathrm{p}<0.05$ \\
NPTE score & $638(49.1)$ & $631(53.7)$ & $643(46.8)$ & $\mathrm{p}<0.05$ \\
\hline
\end{tabular}

Key. ${ }^{*}$ Comparison between campuses. UGPA = undergraduate cumulative GPA; sciGPA = core science undergraduate GPA; prGPA = pre-requisite GPA; tGPA = trend GPA; PTGPA = entry-level program GPA.

Table 2. Regression output of applicant admission variables on PTGPA outcomes.

\begin{tabular}{|lrrrrr|}
\hline Variable & $\boldsymbol{\beta}$ & $\mathbf{t}$ value & $\mathbf{r}$ & $\mathbf{r}^{2}$ & $\boldsymbol{p}$ value \\
\hline UGPA & $\mathbf{0 . 4 9}$ & $\mathbf{6 . 9 9}$ & $\mathbf{0 . 5 0}$ & $\mathbf{0 . 2 5}$ & $<0.01$ \\
sciGPA & -0.08 & -0.61 & 0.09 & 0.01 & 0.55 \\
prGPA & 0.01 & 0.15 & 0.13 & 0.02 & 0.98 \\
tGPA & $\mathbf{0 . 0 5}$ & $\mathbf{0 . 6 7}$ & $\mathbf{0 . 3 9}$ & $\mathbf{0 . 1 5}$ & $<0.01$ \\
GRE & 0.06 & 1.27 & 0.04 & 0.01 & 0.21 \\
Undergraduate degree type & -0.11 & -2.03 & 0.11 & 0.01 & 0.10 \\
Combined Admissions $^{*}$ & & $\mathbf{2 . 4 1}$ & $\mathbf{0 . 5 1}$ & $\mathbf{0 . 2 6}$ & $<0.01$ \\
\hline
\end{tabular}

${ }^{*}$ Combination of applicant admission variables uGPA, sciGPA, prGPA, tGPA, GRE scores, and degree type on PTGPA.

Table 3. Regression output of applicant admission variables on passing NPTE performance.

\begin{tabular}{|lrrrrr|}
\hline Variable & $\boldsymbol{\beta}$ & $\mathbf{t}$ value & $\mathbf{r}$ & $\mathbf{r}^{2}$ & $\mathrm{p}$ value \\
\hline uGPA & $\mathbf{0 . 5 8}$ & $\mathbf{7 . 8 4}$ & $\mathbf{0 . 5 5}$ & $\mathbf{0 . 3 0}$ & $<0.01$ \\
sciGPA & -0.12 & -0.85 & 0.10 & 0.01 & 0.40 \\
prGPA & 0.02 & 0.16 & 0.16 & 0.03 & 0.19 \\
tGPA & $\mathbf{0 . 0 3}$ & $\mathbf{0 . 0 5}$ & $\mathbf{0 . 4 2}$ & $\mathbf{0 . 1 8}$ & $<0.01$ \\
GRE & $\mathbf{0 . 1 1}$ & $\mathbf{2 . 4}$ & $\mathbf{0 . 1 7}$ & $\mathbf{0 . 0 3}$ & $<0.05$ \\
Undergraduate degree type & -0.001 & -0.014 & 0.08 & 0.01 & 0.13 \\
Combined Admissions* & & 1.70 & 0.57 & 0.32 & $<0.01$ \\
PTGPA & $\mathbf{0 . 7 5}$ & $\mathbf{2 1 . 1}$ & $\mathbf{0 . 7 5}$ & $\mathbf{0 . 5 6}$ & $<0.01$ \\
\hline
\end{tabular}

${ }^{*}$ Combination of applicant admission variables uGPA, sciGPA, prGPA, tGPA, GRE scores, and degree type on NPTE. 
Table 4. Crosstabulation of odds-ratios for NPTE performance by sample cut-off scores.

\begin{tabular}{|c|c|c|c|c|}
\hline \multirow[b]{2}{*}{ Applicant Admission Variable } & \multicolumn{4}{|c|}{ Odds-Ratio } \\
\hline & State of variable & $\begin{array}{l}\text { NPTE first-time } \\
\text { "Pass" }\end{array}$ & $\begin{array}{l}\text { NPTE first-time } \\
\text { "No Pass" }\end{array}$ & $\begin{array}{l}\text { Model } \\
\text { Quality* }\end{array}$ \\
\hline \multirow[t]{2}{*}{ uGPA } & Above & 2.89 & 0.12 & 0.79 \\
\hline & Below & 0.15 & 2.28 & \\
\hline \multirow[t]{2}{*}{ sciGPA } & Above & 1.17 & 0.79 & 0.51 \\
\hline & Below & 0.89 & 1.05 & \\
\hline \multirow[t]{2}{*}{ prGPA } & Above & 1.38 & 0.61 & 0.53 \\
\hline & Below & 0.76 & 1.11 & \\
\hline \multirow[t]{2}{*}{ tGPA } & Above & 1.97 & 0.25 & 0.67 \\
\hline & Below & 0.33 & 1.49 & \\
\hline \multirow[t]{2}{*}{ GRE quantitative score } & Above & 1.48 & 0.72 & 0.59 \\
\hline & Below & 1.24 & 1.07 & \\
\hline \multirow[t]{2}{*}{ PTGPA } & Above & 3.94 & 0.10 & 0.87 \\
\hline & Below & 0.20 & 1.96 & \\
\hline \multirow[t]{2}{*}{ Undergraduate degree type } & Science & 1.02 & 0.82 & 0.41 \\
\hline & Non-science & 0.80 & 1.05 & \\
\hline
\end{tabular}

Key. Cut-off values established by first-time initial pass rate on NPTE with $\geq 600$ set as the limiter. UGPA $=$ undergraduate cumulative GPA; sciGPA = core science undergraduate GPA; prGPA = pre-requisite GPA; tGPA = trend GPA; PTGPA = entrylevel program GPA. *Overall model quality is indicated by magnitude where values less than 0.5 are no better than chance, indicating a poor model statistic.

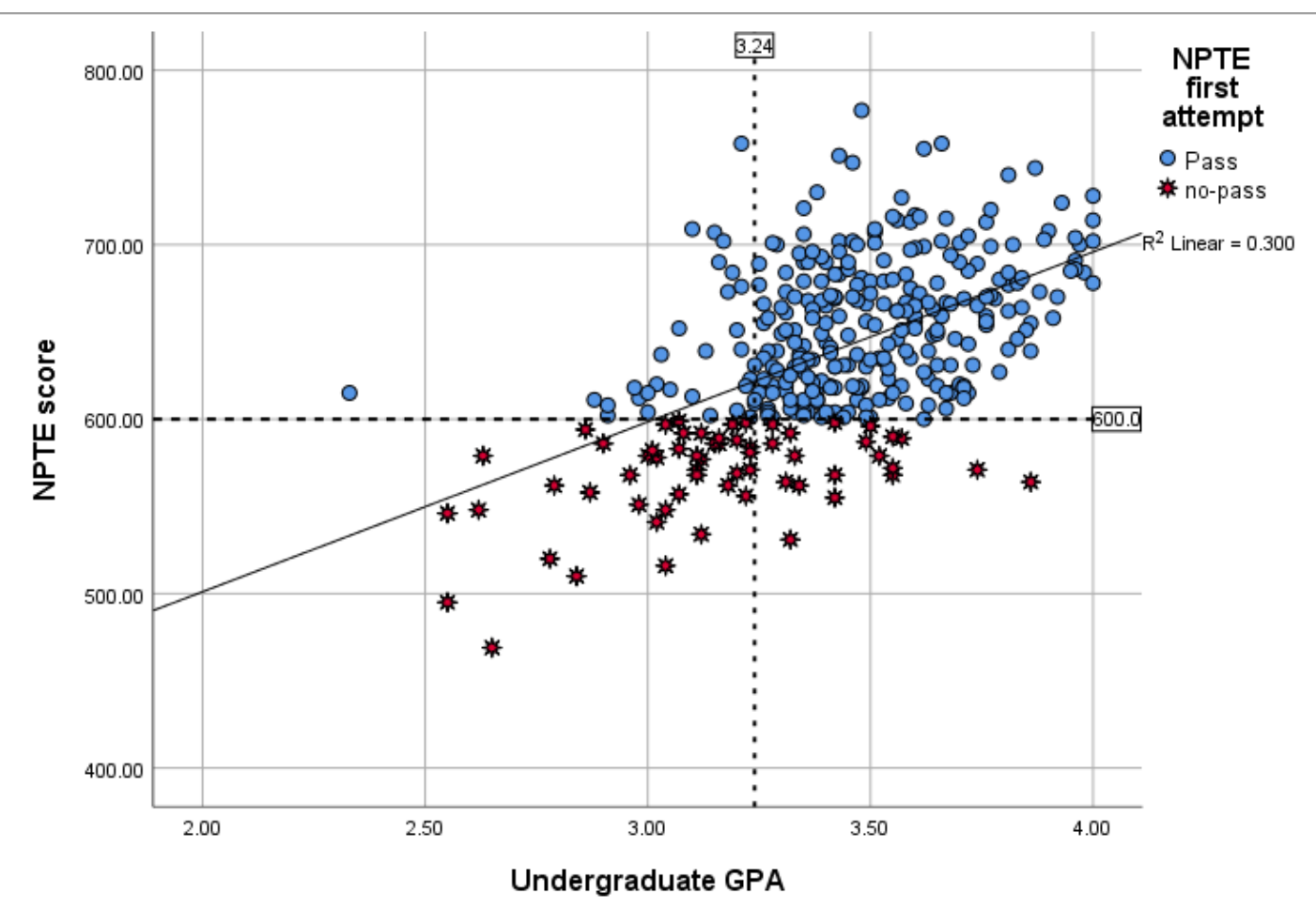

"Figure 1. Relationship between uGPA and NPTE score by sample cut-off scores 


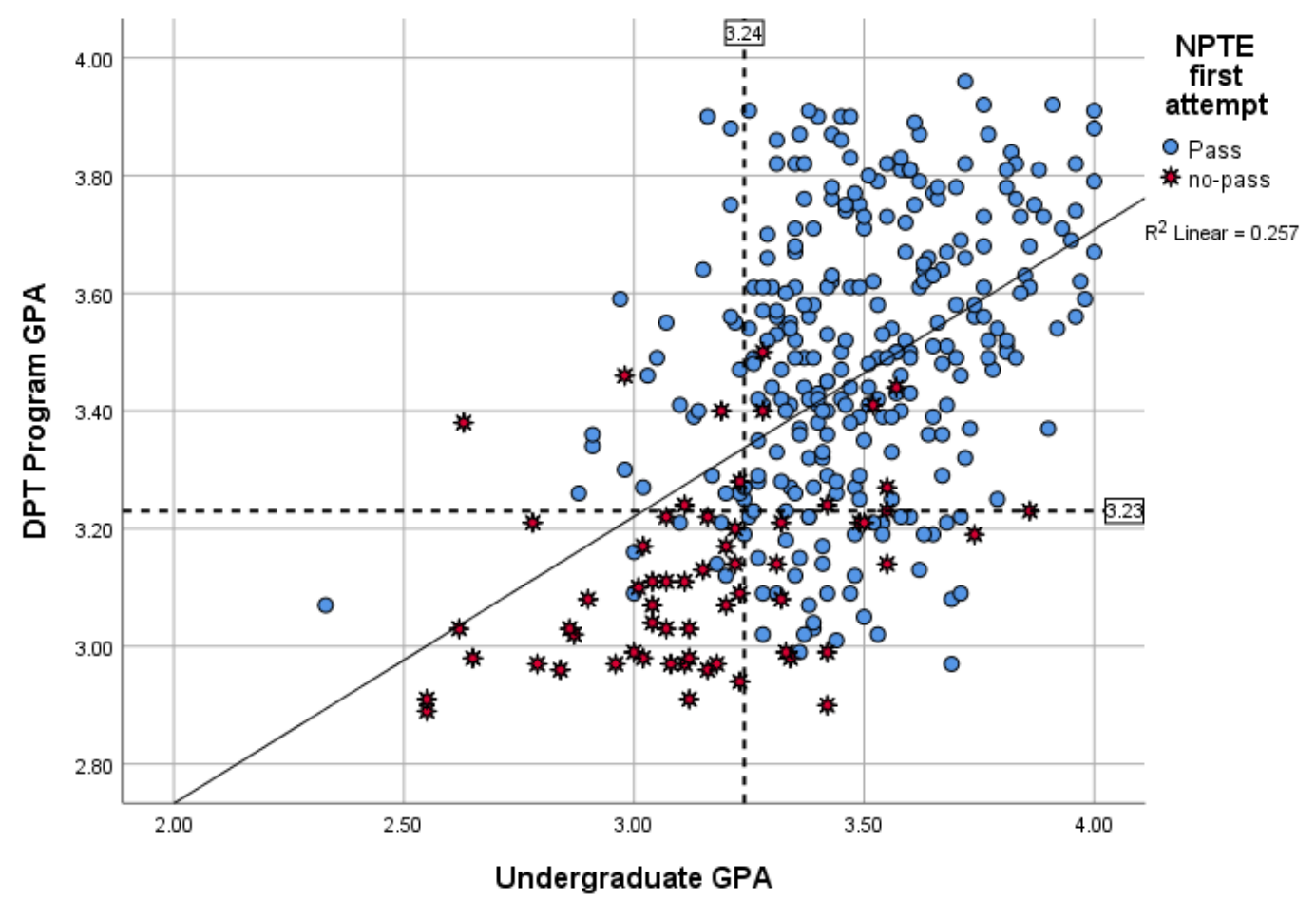

Figure 2. Relationship between UGPA and PTGPA by sample cut-off scores and NPTE pass rate

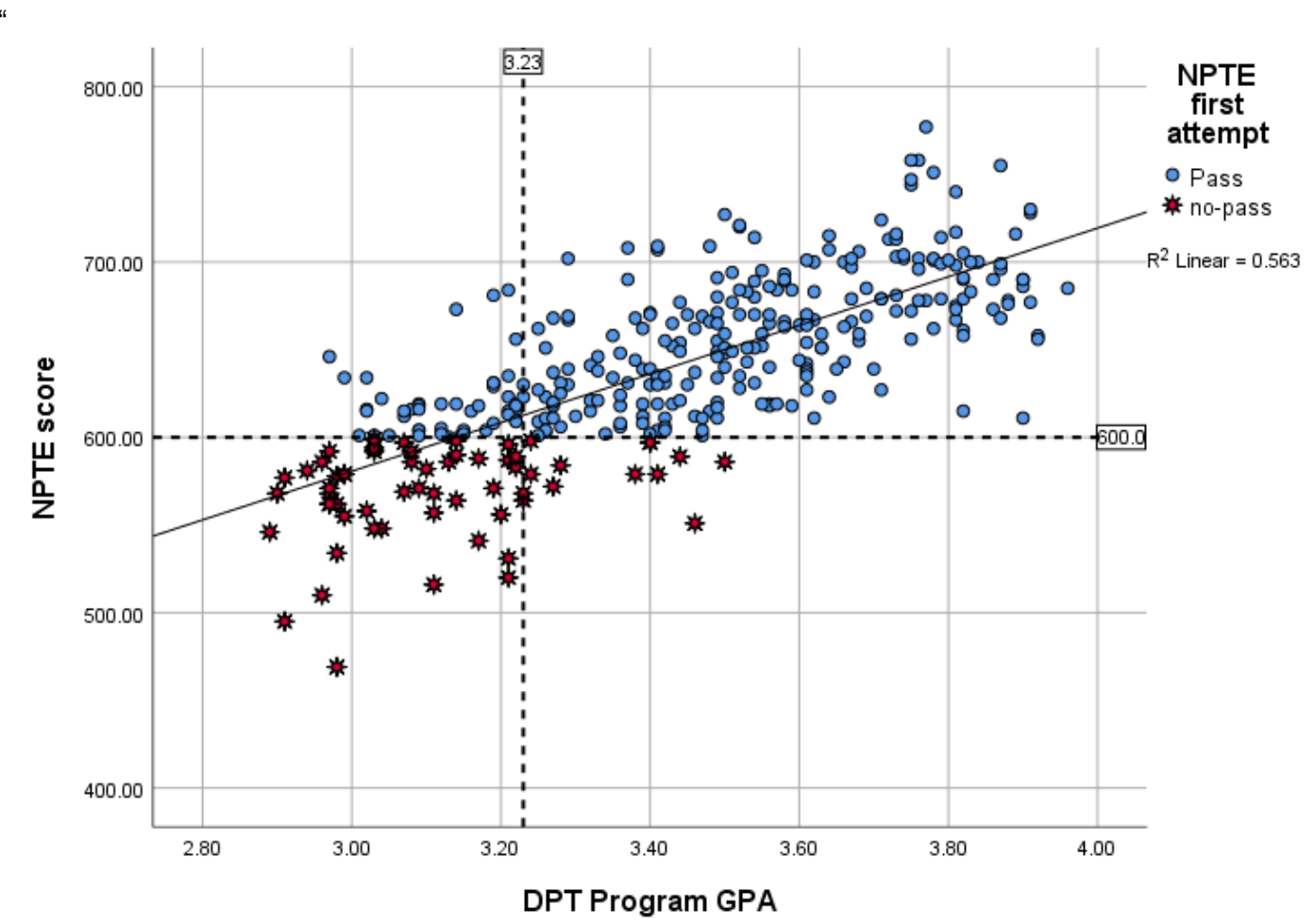

Figure 3. Relationship between PTGPA and NPTE scores by sample cut-off scores. 


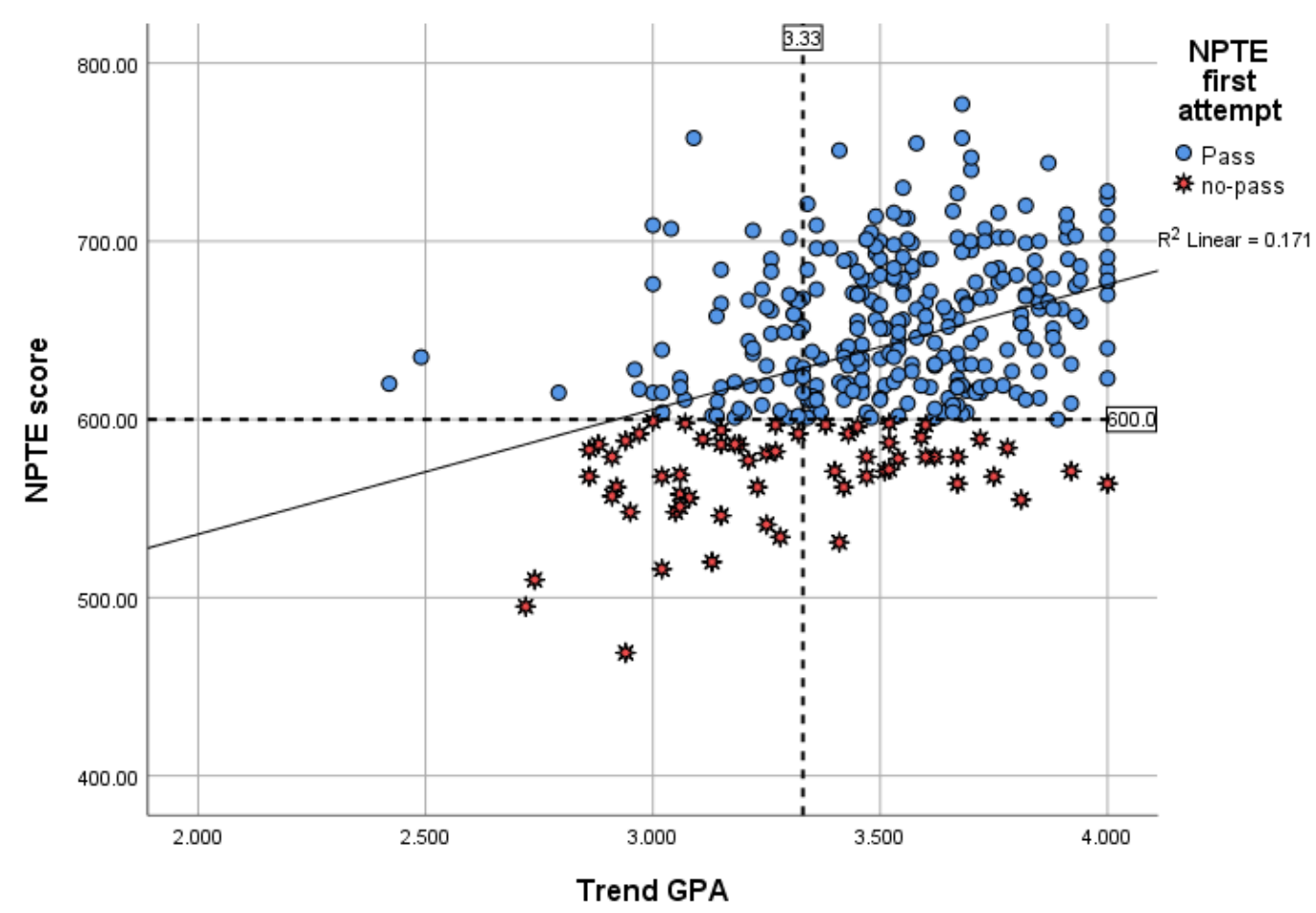

Figure 4. Relationship of tGPA and NPTE scores by sample cut-off scores.

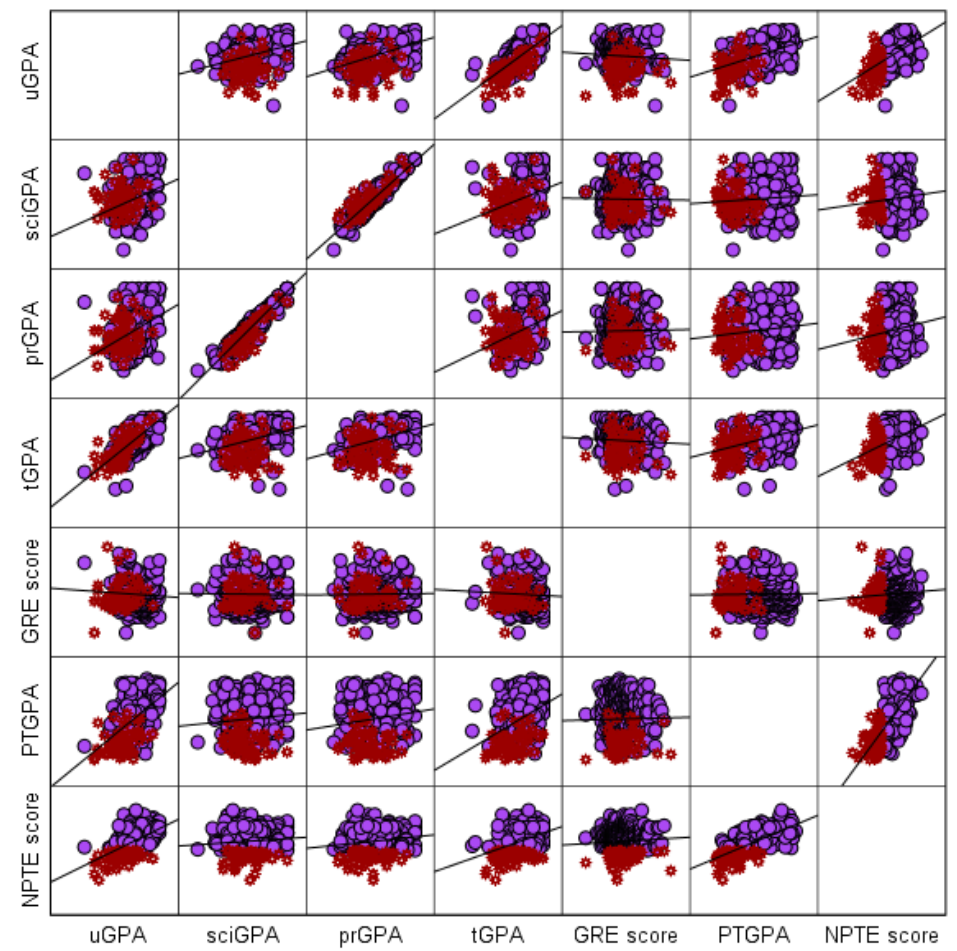

NPTE first

attempt

O Pass

* no-pass

Figure 5. Correlation matrix of predictor variables with NPTE performance. 


\section{DISCUSSION}

The ability to adequately screen and accurately predict stronger from weaker applicants remains critically important to the vitality of any education program. There are a vast array of factors a program may choose to examine as predictors of PT graduate outcomes, including cognitive and non-cognitive characteristics. ${ }^{7,25-33,36-43}$ As such, the study of applicants' admissions characteristics has garnered considerable attention among entry-level DPT education programs. ${ }^{7}$ This study examined the predictive relationships between undergraduate applicant characteristics and graduate outcomes among two entry-level hybridonline DPT programs. During the admissions process, institutions examine many factors but may choose to rely more heavily on certain applicant characteristics. ${ }^{7}$ However, to date, evidence has largely been produced from the study of traditional face-to-face DPT education programs. ${ }^{7}$ This investigation identified factors that may be predictive of future success, specific to hybrid-online DPT programs.

The results of this study suggest that a few select applicant variables may be more indicative of future programmatic success, and perhaps, should be weighted more heavily during admissions decision-making. The total combination of undergraduate applicant predictor variables in this study (uGPA, sciGPA, prGPA, tGPA, and GRE score) was able to explain $26 \%$ of the variation in future PTGPA. However, among applicant characteristics, UGPA and tGPA were the most accurate and significant predictors of future PTPGA. In this sample of hybrid-online DPT students, UGPA, and tGPA explained $25 \%$ and $15 \%$ of PTGPA, respectively. These findings substantiate the theory that strong overall performance in undergraduate work, and a strong conclusion to said work (the final 60 credit hours), appear to be markers of success in hybrid-online DPT education. While none of the remaining applicant variables from this sample were significant predictors of PTGPA they may still have merit in the admissions screening process. Although valuable to consider during the admissions process, quantitative GRE score was found to be a fairly weak predictor of both PTGPA and NPTE performance. These findings are contradictory to some studies where GRE was found to be a strong and significant predictor of future academic performance and NPTE score. These results showed that quantitative GRE scores were only able to predict $1 \%$ and $3 \%$ of variation in PTGPA, and NPTE performance, respectively. The quantitative GRE score report on the readiness of an applicant for graduate school, mostly by measuring general aptitude in math and English. ${ }^{44}$ Thus, the GRE may not adequately assess aspects such as critical thinking, psychomotor learning, or clinical decision-making that are hallmarks required of successful DPT graduates. ${ }^{45}$

Interestingly, sciGPA and prGPA were also found to be weak predictors of both PTGPA outcomes and NPTE performance in this sample of hybrid-online DPT students. Some institutions have a proclivity to prioritize undergraduate scientific preparation and place greater emphasis on sciGPA or science majors. Similarly, the type of undergraduate degree earned, either science or nonscience in nature, was not a significant predictor of success in either PTGPA or NPTE performance. These findings suggest that students from non-science (arts and humanities) backgrounds perform well and a more robust exposure to sciences may not necessarily lead to success in hybrid-online DPT programs. This may be related to varying degrees of preparation in the social sciences and humanities, or that a potential reciprocal effects model (REM) interaction may exist, whereby prior academic achievement and self-concept reinforce one another to yield future academic achievement regardless of the field of study. ${ }^{46}$ Yet, a complete understanding of the REM lay outside the scope of this study. Aside from applicant variables, the single most significant predictor of NPTE scores was PTGPA which accounted for $56 \%$ of the variation in performance. The strength of these findings support much of the prior literature and provide an anchor to new and emerging evidence from hybrid-online programs to previous study from face-to-face programs. ${ }^{47}$ In this sample of hybrid-online DPT students, UGPA and tGPA also explained $30 \%$ and $18 \%$ of NPTE performance, respectively. It appears that undergraduate GPA markers from prior evidence in traditional face-to-face programs possess some degree of durability in hybrid-online DPT education. ${ }^{47}$

Lastly, odds-ratios were calculated for each variable according to first-time NPTE pass rate, and there were some striking observations noted. For example, students with uGPA and tGPA greater than cut-off values were found to have a three-fold and two-fold increase in odds of passing the NPTE on the first attempt, respectively. Whereas students with uGPA less than the established cutoff value were found to have a two-fold increase in failing the NPTE first-attempt. The most convincing results were found with respect to PTGPA whereby values greater than cut-off scores were associated with a four-fold increase in passing the NPTE on the first-attempt. Although, somewhat intuitive, these findings are consistent with prior study and serve to further anchor this study to the growing body of evidence.7,47 Developing entry-level hybrid-online DPT programs could potentially use these findings to establish admissions criteria and monitor outcomes for accreditation purposes. These findings suggest that applicants entering hybrid-online programs with scores associated with future difficulty should be placed into academic support groups for greater emphasis on routine monitoring and academic interventions. ${ }^{47}$

\section{Limitations}

There are limitations to this study. The use of GPA as an outcome has long been critiqued for its variability and calculations of undergraduate GPA scores may be lacking reliability or consistency across institutions. In this study, the final 60 hours of

(c) The Internet Journal of Allied Health Sciences and Practice, 2022 
undergraduate study (tGPA) was computed as a surrogate measure to quantify an applicant's trending academic performance as one progressed through the latter stages of their degree. Consistent with other measurements of GPA, this calculation could potentially be contaminated by various factors. For example, there are unknown elements which may significantly alter one's GPA from one institution to another. Further, tGPA could represent more challenging pre-requisite or science preparation, or less rigorous courses with less impact. None of these elements were discernable or controlled for in this study. However, monitoring tGPA may hold promise in future investigations. Additionally, the sample in this study may have contained a number of students experiencing academic difficulty (i.e., presence of withdrawals and failures). In turn, the nature of including these records in the analysis may have impacted the results to an unknown degree and biased the outcomes in PTGPA and NPTE pass rate. Future investigations may benefit from controlling these covariates, and perhaps, a deeper exploration into the facets of academic difficulty. Future study may consider larger population-based examinations to establish guidance for professional admissions standards on aspects such as the use of the GRE.

\title{
CONCLUSION
}

Hybrid-online learning is quickly becoming the future of higher education and offers many challenges and opportunities for institutions. ${ }^{48}$ Therefore, the accurate screening and selection of entry-level DPT students entering hybrid-online programs has implications for several stakeholders and remains a high priority. Thoroughly screening applicants with evidence-based measurements may potentially reduce academic difficulty, attrition, and prevent unnecessary financial hardship to both students and institutions. ${ }^{47}$ The results from this study highlight the predictive nature of some applicant variables on future success in the two main outcomes of concern: graduating PTGPA and NPTE scores. Since the NPTE is the national standardized examination required for professional licensure and practice it represents the highest level of importance for the accreditation of programs and employment of graduates. ${ }^{7}$ Identifying relationships between applicants' admissions variables and programmatic outcomes would prove beneficial as the size and scale of hybrid-online DPT programs in the US continues to grow.

\author{
Abbreviations \\ APTA - American Physical Therapy Association \\ CAPTE - Commission on the Accreditation of Physical Therapy Education \\ DPT - Doctor of Physical Therapy \\ GPA - grade point average \\ GRE - Graduate Readiness Examination \\ HSRT - Health Science Reasoning Test \\ NPTE - National Physical Therapy Examination \\ prGPA - pre-requisite grade point average \\ PT - Physical Therapy \\ PTGPA - entry-level physical therapy grade point average \\ REM - reciprocal effects model \\ $\mathrm{ROC}$ - receiver operating characteristic \\ $R Q$ - Research questions \\ sciGPA - undergraduate science grade point average \\ tGPA - trend grade point average \\ uGPA - undergraduate cumulative grade point average

\section{Funding} \\ This research did not receive any specific grant funding from agencies in the public, commercial, or not-for-profit sectors.

\section{Conflicts of Interest} \\ The authors have no conflicts of interest to disclose.

\section{REFERENCES} \\ 1. Landry MD, Hack LM, Coulson E, et al. Workforce projections 2010-2020: annual supply and demand forecasting \\ models for physical therapists across the United States. Phys Ther. 2016;96(1): 71-80. PMID: 26472298 \\ 2. https://doi.org/10.2522/pti.20150010 \\ 3. Tepper DE. Opportunities exist in projected workforce demand. APTA Magazine; 2021: Apr 1. Retrieved from: \\ https://www.apta.org/apta-magazine/2021/04/01/opportunities-exist-in-projected-workforce-demand
}


4. U.S. Bureau of Labor Statistics. Occupational outlook handbook: Fastest growing occupations 2016-2026. 2019. https://www.bls.gov/ooh/fastest-growing.htm

5. US News \& World Report. 100 Best Jobs of 2021. Retrieved from: https://money.usnews.com/careers/bestjobs/rankings/the-100-best-jobs

6. Gagnon K, Young B, Bachman T, Longbottom T, Severin R, Walker MJ. Doctor of Physical Therapy Education in a Hybrid Learning Environment: Reimagining the Possibilities and Navigating a "New Normal". Phys Ther. 2020;100(8): 1268-1277. PMID: 32424417

7. Wainwright S. Hybrid Learning: The Perils and Promise of Blending Online and Face-to-Face Instruction in Higher Education. J Phys Ther Educ, 2011;25(1),73.

8. Wolden M, Hill B, Voorhees S. Predicting success for student physical therapists on the national physical therapy examination: Systematic review and meta-analysis. Phys Ther. 2020;100(1):73-89. PMID: 31584670

9. Foo J, Rivers $\mathrm{G}$, llic $\mathrm{D}$, et al. The economic cost of failure in clinical education: a multi-perspective analysis. Medical Education. 2017;51(7): 740-54. PMID: 28326573 DOI: 10.1111/medu.13266

10. Rivers $G$, Foo J, llic $D$, et al. The economic value of an investment in physiotherapy education: a net present value analysis. Journal of Physiotherapy. 2015;61(3): 148-54. PMID: 26093804 DOI: $10.1016 /$ i.jphys.2015.05.015

11. Shields RK, Dudley-Javoroski S. Physiotherapy education is a good financial investment, up to a certain level of student debt: An inter-professional economic analysis. Journal of Physiotherapy. 2018;64(3): 183-91. PMID: 29914805 DOI: $10.1016 /$ i.jphys.2018.05.009

12. Commission on Accreditation in Physical Therapy Education. Aggregate program data: 2019-2020 Physical Therapist Education Fact Sheets. 2020; Mar 10. Retrieved from: https://www.capteonline.org/globalassets/captedocs/aggregate-data/2019-2020-aggregate-pt-program-data.pdf

13. Friedman Z. Student loan debt statistics in 2018: A \$1.5 trillion crisis. Forbes. 2018; Jun 13.

14. Jette DU. Physical therapist student loan debt. Phys Ther. 2016;96(11):1685-8. PMID: 27803293 DOI: $10.2522 / p t j .20160307$

15. Jewell DV, Riddle DL. Method for predicting a student's risk for probation in a professional program allied health. Journal of Allied Health. 2005;34(1):17-23. PMID: 15839601

16. Riddle DL, Utzman RR, Jewell DV, Pearson S, Kong X. Academic difficulty and program-level variables predict performance on the national physical therapy examination for licensure: a population-based cohort study. Phys Ther, 2009;89(11), 1182-1191. PMID: 19762483 DOI: 10.2522/ptj.20080400

17. Roman G, Buman MP. Preadmission predictors of graduation success from a physical therapy education program in the United States. J Educ Eval Health Prof. 2019;16. PMID: 30803203

18. Coleman-Salgado $B, B$ arakatt $E$. Identifying demographic and preadmission factors predictive of success on the national physical therapy licensure examination for graduates of a public physical therapist education program. $J$ Phys Ther Educ, 2018;32(1), 8-16.

19. Fell N, Mabey R, Mohr T, Ingram D. The preprofessional degree: is it a predictor of success in physical therapy education programs?. J Phys Ther Educ, 2015;29(3), 13-21.

20. Utzman RR, Riddle DL, Jewell DV. Use of demographic and quantitative admissions data to predict performance on the national physical therapy examination. Phys Ther, 2007;87(9), 1181-1193. PMID: 17609335 DOI: $10.2522 / p t j .20060222$

21. Pucillo EM, Kiernan E, Shotwell MP, Crossen-Sills J. Learning strategies and academic difficulty in occupational and physical therapy online education. J Occup Ther Educ. 2020;4(2):5.

22. Terry R, Hing W, Orr RM, Milne N. Undergraduate Grade-point Average as a Selection Criterion for a Postgraduate Entry-level Physiotherapy Program. Aust J Clin Educ, 2018;3(1), 1-17.

23. Meiners KM, Rush DK. Clinical performance and admission variables as predictors of passage of the national physical therapy examination. Journal of Allied Health, 2017;46(3), 164-170. PMID: 28889166

24. Kosmahl EM. Factors related to physical therapist license examination scores. J Phys Ther Educ. 2005;19(2):52-56.

25. Kume J, Reddin V, Horbacewicz J. Predictors of physical therapy academic and NPTE licensure performance. Health Prof Educ. 2019;5(3):185-193.

26. Huhn K, Rusinski DPT B, Saucier DPT A, et al. Exploration of Grit and Emotional Intelligence and Success in a Doctor of Physical Therapy Program. Int J All Health Sci Prac. 2021;19(1):10.

27. Huhn K, Parrott SJ. Exploration of relationships among the health sciences reasoning test, the national physical therapy licensing examination, and cognitive admission variables. J Phys Ther Educ. 2017;31(1):7-13. 
28. Hawkins C. The Impact of a Holistic Admissions Review Process in a Doctor of Physical Therapy Program. 2020 (Doctoral dissertation, Bellarmine University). Retrieved from: https://scholarworks. bellarmine.edu/cgi/viewcontent.cgi?article=1096\&context=tdc

29. Bayliss J, Thomas RM. Pilot Study: What Measures Predict First Time Pass Rate on the National Physical Therapy Examination? Int J All Health Sci Prac. 2017;15(4):1.

30. Bliss R, Jacobson E. Doctor of Physical Therapy Student Grit as a Predictor of Academic Success: A Pilot Study. Health Professions Education. 2020;6(4):522-528.

31. Galleher $C$, Rundquist PJ, Barker DB, Chang WP. Determining cognitive and non-cognitive predictors of success on the National Physical Therapy Examination. Int J All Health Sci Prac, 2012;10(4), 7.

32. Wheeler E, Finucane S, Soper S, Mayhew T. Perceived Value of Preadmission Physical Therapy Observation Hours and Their Ability to Predict Academic Performance. J Phys Ther Educ, 2018;32(1), 17-25.

33. Carp S, Fry K, Gumerman B, Pressley K, Whitman A. Relationship between grit scale score and academic performance in a doctor of physical therapy program: A case study. Journal of Allied Health. 2020;49(1):29-36. PMID: 32128536

34. Flowers DW, Bernard A. Make Changes Early! High Stress Levels Predict Lower Academic Performance in First-Year Physical Therapy Students: A Pilot Study. Int J All Health Sci Prac. 2020;18(4):15.

35. Portney LG, Watkins MP. Foundations of Clinical Research: Applications to Practice (3rd ed.). 2015. Upper Saddle River, NJ: Pearson, Inc.

36. IBM Corp. Released 2020. IBM SPSS Statistics for Windows, Version 27.0. Armonk, NY: IBM Corp.

37. Cook C, Engelhard C, Landry MD, McCallum C. Modifiable variables in physical therapy education programs associated with first-time and three-year National Physical Therapy Examination pass rates in the United States. $J$ Educ Eval Heal Prof; 2015, 12. PMID: 26395081

38. Cook CE, Landry MD, Covington JK, et al. Scholarly research productivity is not related to higher three-year licensure pass rates for physical therapy academic programs. BMC Med Educ, 2015;15(1), 148. PMID: 26362434

39. Dickson T, Taylor B, Zafereo J. Characteristics of Professional Physical Therapist Faculty and Doctor of Physical Therapy Programs, 2008-2017: Influences on Graduation Rates and First-Time National Physical Therapy Examination Pass Rates. Phys Ther. 2020;100(11):1930-1947. PMID: 32750145 DOI: 10.1093/ptj/pzaa148

40. Covington K, McCallum C, Engelhard C, Landry MD, Cook C. Do Differences in Programmatic Resource Investments Result in Different 3-Year Pass Rates on the US National Physical Therapy Examination? Journal of Allied Health, 2016; 45(1), 27-32. PMID: 26937879

41. Thieman TJ, Weddle ML, Moore MA. Predicting academic, clinical, and licensure examination performance in a professional (entry-level) master's degree program in physical therapy. J Phys Ther Educ, 2003;17(2): 32.

42. Vendrely AM. An investigation of the relationships among academic performance, clinical performance, critical thinking, and success on the physical therapy licensure examination. Journal of Allied Health. 2007;36(2):108-123.

43. Kuo YL. Relationship among Study Strategies, Course Grades, and Success on the Taiwanese National Physical Therapy Examination. 醫學教育, 2015;19(1): 1-10.

44. Graduate Readiness Examination. About the Test: Fairness and Validity. 2021. Retrieved from: https://www.ets.org/gre/revised_general/about/fairness/

45. Dehan J. (2018). Predictive Ability of Specific Professional Courses for Passage of the National Physical Therapy Examination in Midwestern Universities (Doctoral dissertation, Saint Louis University). Retrieved from: https://eric.ed.gov/?id=ED595585

46. Marsh HW, Martin AJ. Academic self-concept and academic achievement: relations and causal ordering. Br J Educ Psychol. 2011;81(Pt 1):59-77. PMID: 21391964 DOI: 10.1348/000709910X503501

47. Mitchell K, Ellison J, Schaumberg E, et al. Examining Demographic and Preadmission Factors Predictive of First Year and Overall Program Success in a Public Physical Therapist Education Program, J Phys Ther Educ. 2021;35(3): 203209. DOI: $10.1097 /$ JTE.0000000000000186

48. Joosten T, Weber N, Baker M, Schletzbaum A, McGuire A, et al. Planning for a Blended Future: A Research-Driven Guide for Educators. [Report] Every Learner Everywhere Network. Online Learning Consortium. 2021. Retrieved from: www.everylearnereverywhere.org/resources/ 